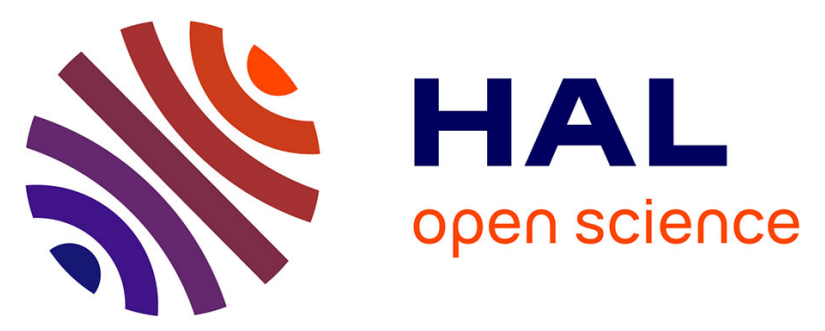

\title{
Fuzzy Approach for Bibliometric Analysis of Publication Trends on Intragastric Balloon as a Minimally Invasive Procedure for Weight Loss in Obese Individuals
} Trasanides George, Tsaousi Georgia, Adjenughwure Kingsley, Kotzampassi Katerina, Kapanidis Konstantinos, Papadopoulos Basil

\section{To cite this version:}

Trasanides George, Tsaousi Georgia, Adjenughwure Kingsley, Kotzampassi Katerina, Kapanidis Konstantinos, et al.. Fuzzy Approach for Bibliometric Analysis of Publication Trends on Intragastric Balloon as a Minimally Invasive Procedure for Weight Loss in Obese Individuals. 14th IFIP International Conference on Artificial Intelligence Applications and Innovations (AIAI), May 2018, Rhodes, Greece. pp.580-591, 10.1007/978-3-319-92007-8_49 . hal-01821071

\section{HAL Id: hal-01821071 \\ https://hal.inria.fr/hal-01821071}

Submitted on 22 Jun 2018

HAL is a multi-disciplinary open access archive for the deposit and dissemination of scientific research documents, whether they are published or not. The documents may come from teaching and research institutions in France or abroad, or from public or private research centers.
L'archive ouverte pluridisciplinaire HAL, est destinée au dépôt et à la diffusion de documents scientifiques de niveau recherche, publiés ou non, émanant des établissements d'enseignement et de recherche français ou étrangers, des laboratoires publics ou privés. 


\title{
Fuzzy approach for bibliometric analysis of publication trends on intragastric balloon as a minimally invasive procedure for weight loss in obese individuals.
}

\author{
Trasanides George $^{2}$, Tsaousi Georgia ${ }^{1}$, Adjenughwure Kingsley ${ }^{2}$, \\ Kotzampassi Katerina $^{1}$, Kapanidis Konstantinos ${ }^{1}$, Papadopoulos Basil ${ }^{2}$ \\ ${ }^{1}$ Department of Surgery, Faculty of Medicine, Aristotle University Thessaloniki, University \\ Campus, 54006, Thessaloniki, Greece. \\ ${ }^{2}$ Department of Civil Engineering, Democritus University of Thrace
}

\begin{abstract}
In this paper, we perform Bibliometric assessment of research output that has been carried out pertaining to the literature on intragastric balloon (IGBs) as a treatment modality of morbid obesity. To do this, we conducted a bibliometric analysis on this topic using the growth of publications, publication trends over time, annual research productivity and authors' activity as main outcome points. Furthermore, we validate the comparable applicability of Lotka's law among authors with a single publication and those with multiple ones using a fuzzy approach. The analysis shows that publication trend follows Price's law. The extracted trend is exponential and in accordance with what is found in other studies. Lotka's formula using one and two publications, is found to hold but for mean $x=3.025$.
\end{abstract}

Keywords: Fuzzy estimators, bibliometric analysis, fuzzy sets, Bariatric Surgery, intragastric balloon, Lotka's law

\section{Introduction}

Obesity constitutes a worldwide epidemic socio-economic entity incurring se-rious repercussions on health status and exacerbation of obesity-related co-morbidities (Laing P et al, 2017; Flegal KM et. al, 2010). These seem to exert an adverse impact on both life quality and expectancy of obese individuals, all lead-ing to spiralling health costs (Cawley J, Meyerhoefer C,2012).

Although, lifestyle / behavioural and diet modification assisted by physical exercise is recommended as a first line approach to weight loss, yet numerous studies failed to support a sustainable effectiveness for the vast majority of those who attempted such practice (Norris SL et.al,2005). As to pharmacotherapy, which is considered as the second line approach, a modest efficacy associated with significant side-effects has been documented (Yanovski SZ, Yanovski JA,2014).

Thus, bariatric surgery emerges as the most reliable treatment modality for the management of severe obesity, with long-term efficacy in weight loss(Colquitt JL et 
al,2013; Buchwald H, Oien DM,2014). Nonetheless, the substantial cost and non-negligible surgical morbidity and mortality render bariatric surgery as a less attractive option for obese patients to pursue( Jirapinyo P, Thompson CC,2017; Buchwald H, Oien DM,2014).

To fill the void, minimally invasive non-surgical options for weight loss are gaining popularity; the intragastric balloon (IGB) being the most widely applied in clinical practice (Laing P et al, 2017; Yorke E, et al,2016 ). The fundamental concept of an IGB is the attainment of a continuous sensation of satiety owing to mechanical gastric distension caused by an artificial gastric bezoar, thereby facil-itating decreased food intake and maintenance of a low-calorie diet (Kumar N et al 2017; Laing P et al, 2017; Yorke $\mathrm{E}$, et al,2016 ). Its versatility, low invasive-ness, ease of retrieval and relative safety has resulted in the broad acceptance of its use with thousands of devices placed globally each year(Yorke E, et al,2016 ). Consequently, numerous publications have assessed the applicability of various types of IGBs from their inception to clinical practice up to nowadays(Laing P et al, 2017; Yorke E, et al,2016; Kotzampassi K et al,2012; Kotzampassi K et al,2014) .

Bibliometric analysis incorporates statistical and mathematical methods with a view to provide a quantitative and qualitative analysis of scientific evidence, as well as the course of research performance and productivity on a certain scien-tific topic and period of time(Ellegaard O, Wallin JA ,2015; Mishra L et. al,2016; Thompson DF, Walker CK,2015). Bibliometric indicators have been extensively used in various medical disciplines to outline research trends, sug-gest future research ideas and challenge public health issues(Khan NR et al,2014;. Sweileh WM et al ,2015, Zyoud SH et al,2015 )

In the recent literature, several bibliometric analyses have attempted to elucidate publication productivity regarding the implementation of bariatric surgery as a treatment modality of severe obesity (Aminian A, et al 2015; Ozsoy Z,\& Demir E, 2017; Dabi Y eta al ,2016) or to comparably assess bariatric procedures in terms of their popularity (Ozsoy Z, \&Demir E..,2018).

To the best of our knowledge, no bibliometric assessment of research output has been carried out pertaining to the literature on IGBs as a treatment modality of morbid obesity, for the 25-year period (1982 to 2017) this technique has come into clinical effect.

Thus, we conducted this bibliometric analysis on this topic using the growth of publications, publication trends over time, annual research productivity and au-thors' activity as main outcome points. Furthermore, we aimed to validate the comparable applicability of Lotka's law among authors with a single publication and those with multiple ones using a fuzzy approach.

\section{Materials and Methods}

\subsection{Data Source and Description}

The data used in this study were sourced from Scopus database. The terms Bintragastric balloons ${ }^{\wedge}$ and Bobesity ${ }^{\wedge}$ with Band $^{\wedge}$ as Boolean term were used as keywords entered into the Scopus engine to retrieve data related to the objectives of this study. A search 
of these terms was confined to the article title, abstract and keywords of document search. The accuracy of search query was achieved with quotation marks.

Documents from all subject areas, with no time period limitation and language restriction, were retrieved. Only articles published as an erratum were excluded. Search was accomplished on 20 December 2017 to avoid any bias addressed to the daily updating of the database.

Data on overall scientific production regarding the use of IGBs for obesity management were analysed for the overall growth of publications, annual re-search productivity, authors' activity, etc. To verify Lotka's law, a fuzzy approach was used.

A total of 569 articles were retrieved and further analyzed. Published articles on the use of IGBs for obesity management assessed in this study cover a time-period between 1982 up to the end of 2017. Temporal distribution of production of publications is presented in Figure 1.

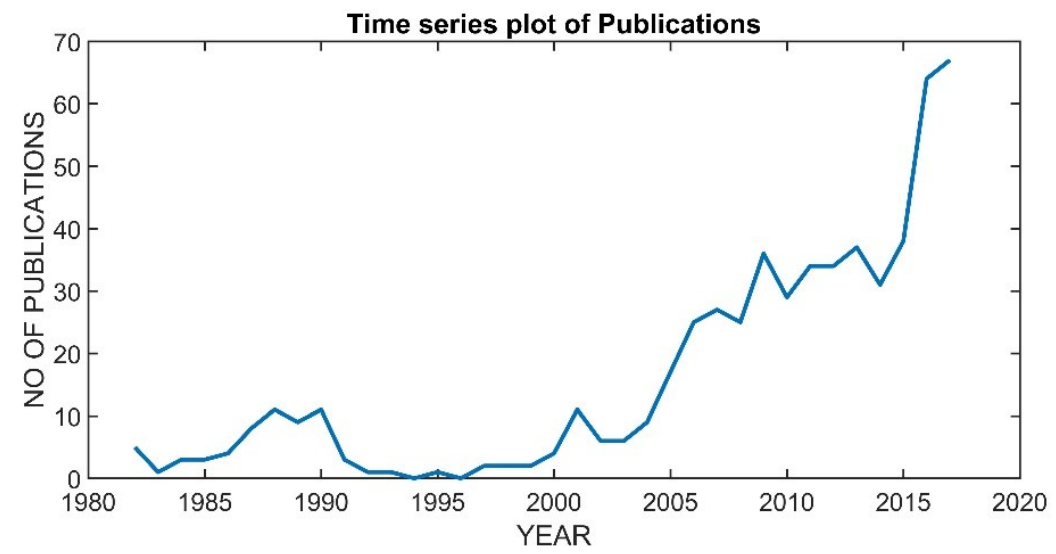

Fig. 1. Timeseries of New Publications per year in the domain

Analysis of authors' productivity revealed that a total of 2001 authors contributed to the published articles. The average number of authors per article was 3.41. Detailed data on authors' activity is provided in Table 1 .

Ethical approval of this study was not deemed necessary since no human sub-jects or data were involved. 
Table 1. Authors' Activities

\begin{tabular}{|c|c|c|}
\hline No of authors & No of articles & Percentage $\%$ \\
\hline 1533 & 1 & 76,7 \\
\hline 466 & $>1$ & 23,3 \\
\hline 290 & 2 & 14,5 \\
\hline 73 & 3 & 3,65 \\
\hline 95 & $>10$ & 4,75 \\
\hline 8 & 11 to 27 & 0,4 \\
\hline
\end{tabular}

\subsection{Data Analysis Techniques}

This analysis has two parts, first we look at the publication trend by analysing the time series of publications. The trend is extracted from the original series using the singular spectrum analysis technique(Golyandina, N, et al,2001; Has-sani H,2007). Singular Spectrum Analysis (SSA) is a relatively new technique for time series decomposition, reconstruction and prediction. The SSA is a two-stage process.

The first stage is the decomposition of the series and the second stage is the reconstruction of the decomposed series to get the original series. The decomposition of the series is done in two steps namely: embedding and Singular Value Decomposition (SVD). The reconstruction of the original series is done by diagonal averaging of the resulting matrix after and optional grouping of the eigenvalues step has been completed. The mathematical description of all the steps mentioned above is presented in (Golyandina, N, et al,2001; Hassani H,2007).

This technique is chosen, because it allows the timeseries to be divided into a sum of many time series with different periods and extract noise. There is no need to specify the shape of the trend beforehand.

In the second part of analysis, we try to verify, if the number publication pattern follows Lotka's law. $n_{i}=n_{1} / i^{x} \quad$. Where $n_{i}$ is the number of authors with $i$ publications and $n_{1}$ is the number of authors with one publication and $x$ is a positive real number usually assumed to be 2 . In the analysis, we focus on authors with one and two publications. For this surgical procedure, there were not enough number of authors with more than 2 publications. Thus, we chose to verify $n_{2}=n_{1} / 2^{x}$. In contrast to other studies, we do not assume that the number of publications is deterministic but we assume them to be stochastic in nature. This is a valid assumption, since we do not expect the number of publications to exactly follows Lotka's law. So, we assume that $n_{1}, n_{2}$ and $x$ are random variables whose sampling distribution follows a normal distribution. These assumptions allow us to calculate the $95 \%$ confidence interval for $n_{1}, n_{2}$ 
and $x$ using the sample estimate for the means and standard deviations of these variables. To correctly propagate the error in estimation, a fuzzy approach is adopted. In this approach, all confidence intervals, are converted to fuzzy numbers using the procedure described in (Buckley J J,2005; Sfiris, D. S., \& Papadopoulos, B. K.,2014) A description of the fuzzy theory and fuzzy estimators is presented in (Buckley J J,2005; Sfiris, D. S., \& Papadopoulos, B. K.,2014).

\section{Results and Discussion}

\subsection{Time series components}

We split the time series into a sum of 15 series. This is to enable us detect any seasonality in the publications. As can be seen from the figure below, there is strong 5 years seasonality where publication number increase and decrease every 5 years. Apart from this, there are no other strong seasonality. It can be concluded that the time series is made of an increasing trend and a 5 year- periodic trend.
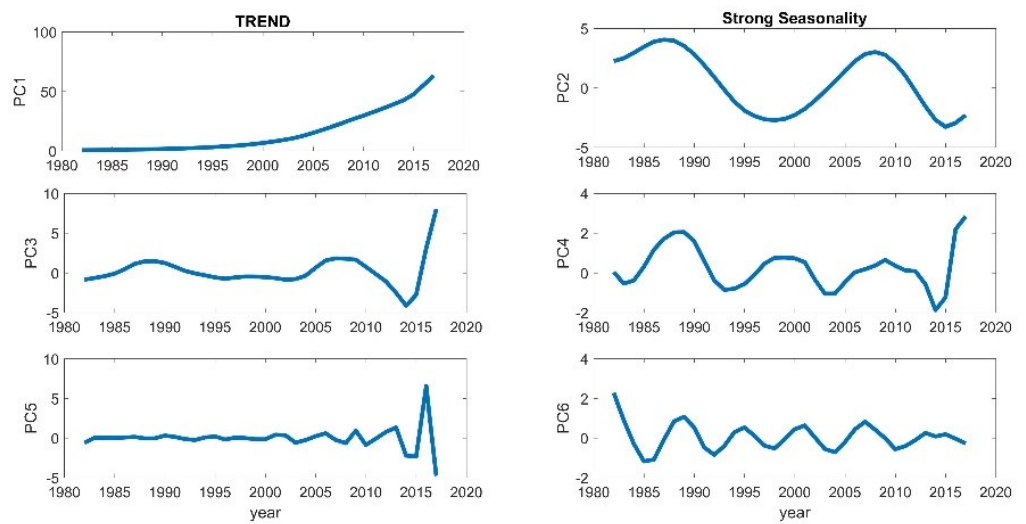

Fig. 2. First 6 Timeseries components as extracted by SSA technique

\subsection{Trend Extraction and Fitting}

The SSA technique was used to extract the trend of the original time series without specifying its form. The only parameter needed for the extraction is the window length, $\mathrm{L}$ which was chosen to be 15 (procedure for choosing the lag is explained in the (Golyandina, N, et al,2001; Hassani H,2007). The extracted trend shows an exponential increase in number of publications as expected following Price's law. An exponential function is fitted to the observed data. The fitted function is in line with Prices' law and corresponds to those results found in (Dabi Y, et al,2016). 


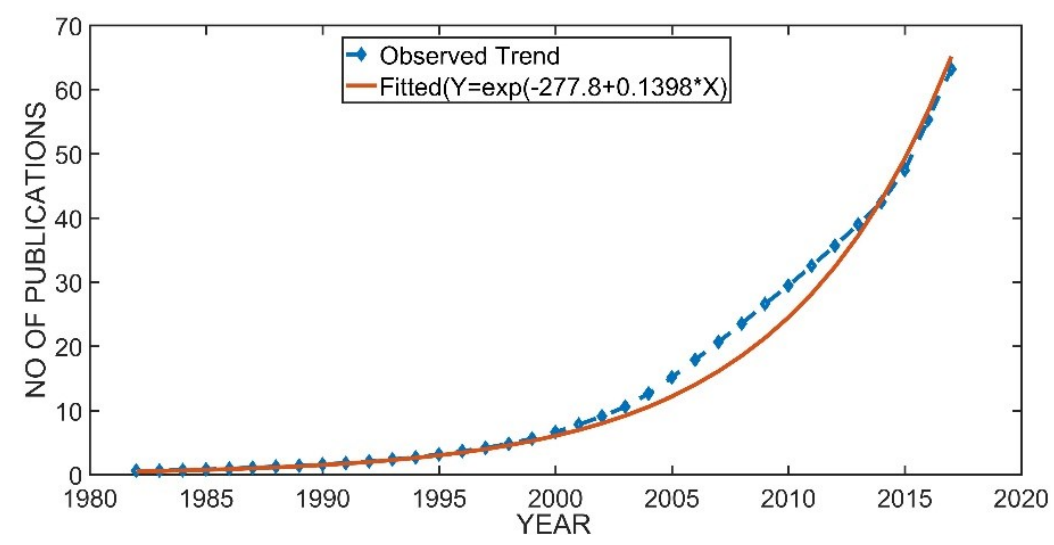

Fig. 3. Price's Law exponential fitting of publication trend

\subsection{Verification of Lotka's Law with fuzzy estimators}

To verify Lotka's law, we assume that the number of authors with 1 and 2 pub-lications is stochastic. Since we do not know the true distribution, we use the sampling distribution and assume that it follows a t-distribution since the sample mean and unbiased sample standard deviation are used.

We construct the $95 \%$ confidence interval for $n_{1}$ and $n_{2}$, and transform the intervals to fuzzy numbers using the approach described in (Buckley J J,2005; Sfiris, D. S., \& Papadopoulos, B. K.,2014). (Please see appendix for description of method). We then use the formula $n_{2}=n_{1} / 2^{x}$ to calculate $x$. Then the $95 \%$ confidence interval for $x$ is also calculated and transformed to a fuzzy number. The goal is to check whether for the estimated $x$

$$
\frac{n_{1}}{n_{2}}-2^{x}=0
$$

We perform the $\alpha$-cut operation on the equation above as follows(see (Buckley $\mathrm{J}$ J,2005; Sfiris, D. S., \& Papadopoulos, B. K.,2014). for arithmetic on alpha-cuts):

$$
\frac{{ }^{\alpha} \tilde{n}_{1}}{{ }^{\alpha} \tilde{n}_{2}}-2^{\alpha} \tilde{x}=0
$$

Where $\tilde{n}_{1}, \tilde{n}_{2}, \tilde{x}$ are fuzzy numbers

The resulting fuzzy numbers are shown below: 


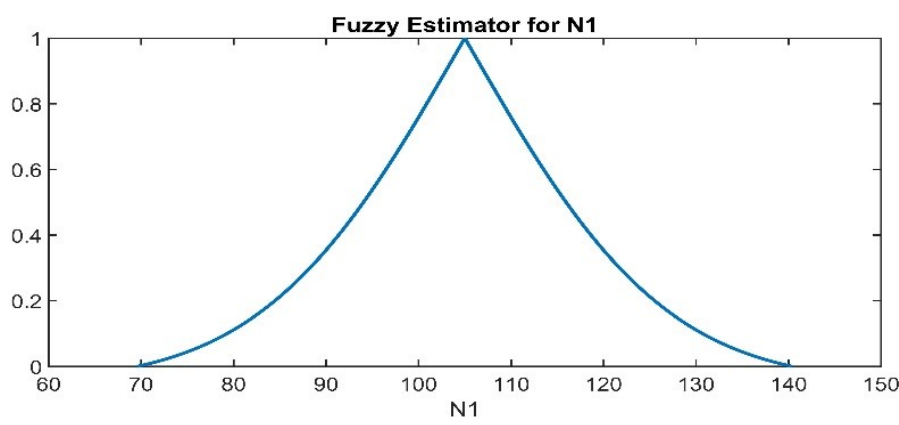

Fig. 4. Fuzzy estimation for number of authors with one publication (mean value has a truth value of 1 )

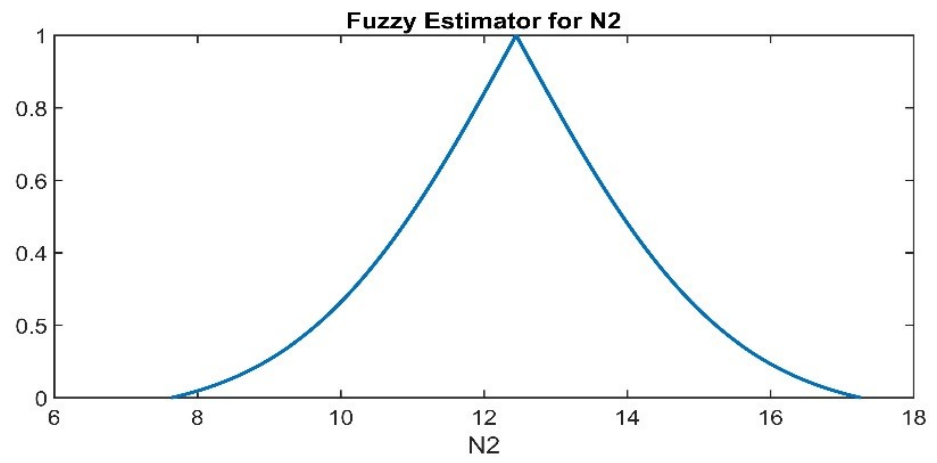

Fig. 5. Fuzzy estimation for number of authors with two publications (mean value has a truth value of 1

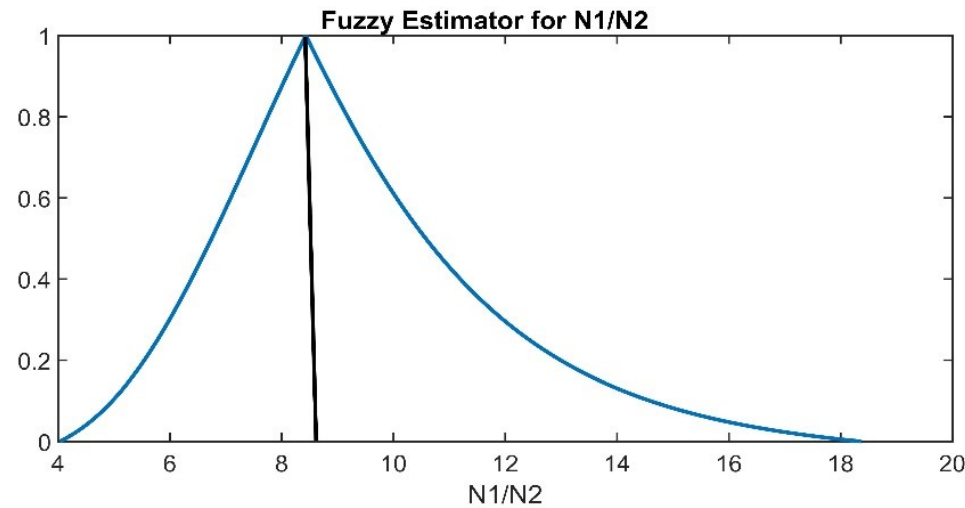

Fig. 6. Fuzzy estimation for the ratio of number of authors with one publication to the number of authors with two publications(mean value has a truth value of 1 ) 


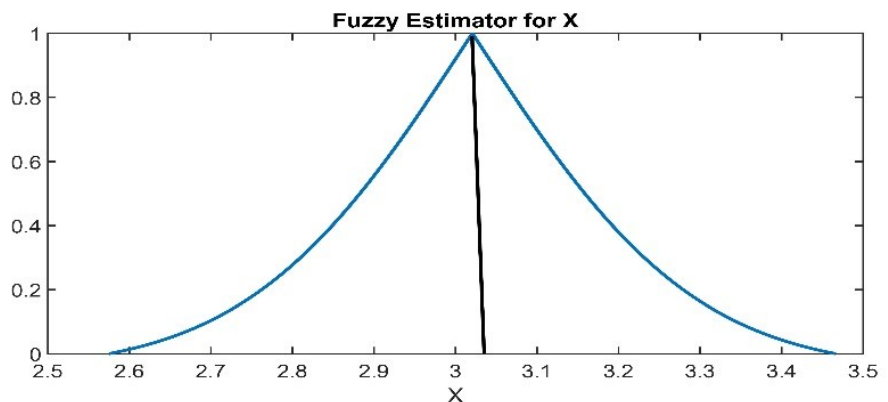

Fig. 7. . Fuzzy estimation for the estimated parameter $x($ mean value has a truth value of 1$)$

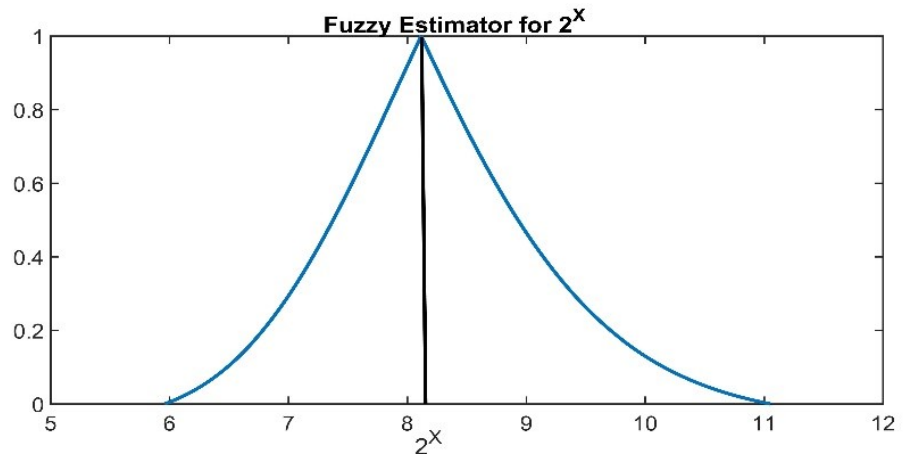

Fig. 8. Fuzzy estimation for the exponent $2^{\mathrm{x}}$ (mean value has a truth value of 1$)$

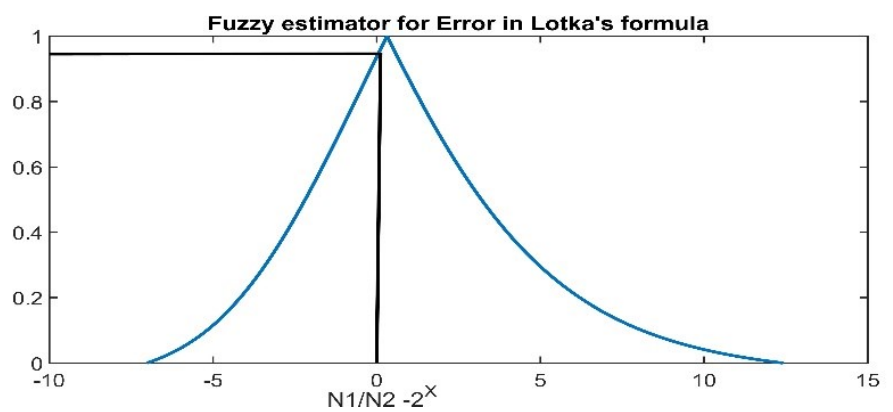

Fig. 9. Fuzzy estimation for the error in Lotka's formula ( possibility of error zero is approximately 0.95 ) 
The fuzzy estimator for the error in Lotka's formula shows that, publication trend indeed follows the given formula but with average $x=3.0208$. Using this value of $x$, then the formula is considered accurate to a degree of 0.95 . This is a pretty high truth value which verifies that it can be used to predict number of authors with two publications. From the fuzzy number of $x$, it can be concluded that $x=2$ is highly unlikely, since its truth value equals zero. Thus, the usual Lotka's formula where $\mathrm{x}=2$ does not hold in this case.

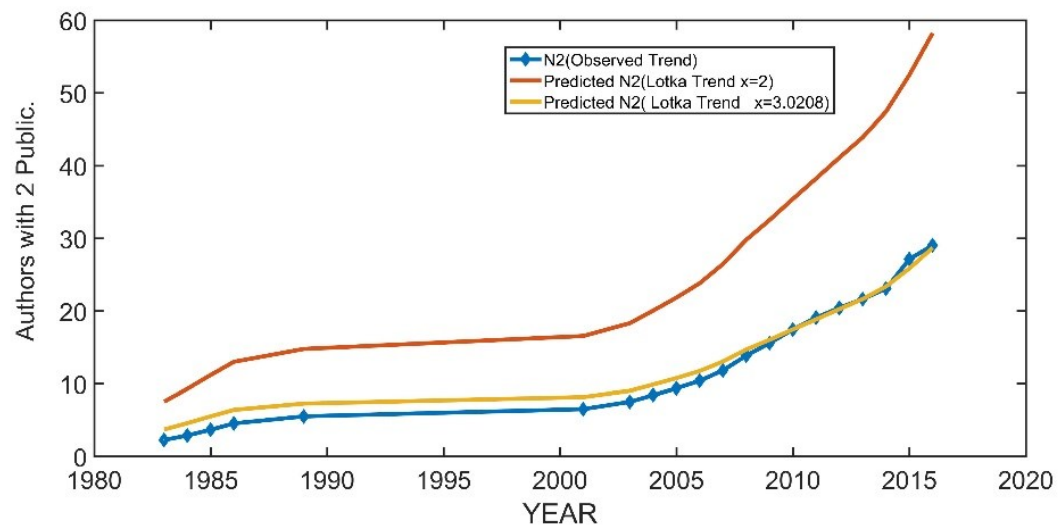

Fig. 10. Publication trend for authors with 2 publications showing observed and estimated trend for $\mathrm{x}=2$, and $\mathrm{x}=3.0208$

\section{Conclusion}

As the prevalence of serious obesity is constantly increased, there is a growing pressure on medical research for the evolvement of less-permanent procedures, as alternatives to surgical ones, aiming to achieve a sustainable weight loss effect that outweighs the morbidity associated with bariatric surgery.

Use of IGBs emerges as a technically easier and of minimal-risk procedure en-suring a significant weight loss in selected obese patients(Kotzampassi K et al,2012). IGBs being currently in practice are delivered endoscopically into the stomach to reduce gastric capacity and inflated with either saline or air. It has been advocated as an effective method of inducing adequate weight loss in non-morbid obesity for whatever reason or aesthetic purposes, prior to a more definitive treatment through bariatric surgery in an attempt to minimize complication rates and technical difficulties of surgery or as an adjunct to conservative treatment in the morbidly obese denied anaesthesia and/or surgery (Fernandes M et al,2007, Kotzampassi K et al,2006, Kotzampassi K et al,2008). Typically, IGB devices are removed after 6 months, as the risk of balloon deflation and possible migration is heightened substantially beyond this time-period (Papavramidis TS et al,2012). 
Bibliometric analysis is regarded as one scientometry tool used to assess the scientific activities, according to the four major domains of published articles, such as authors, citations, references and publications. In the present study we decided to evaluate both the trend of publications and alos verify Lotka's law using a fuzzy approach. The analysis shows that publication trend follows Price's law. The extracted trend is exponential and in accordance with what is found in other studies. Lotka's formula using one and two publications, is found to hold but for mean $x=3.025$. Thus using the original value $\mathrm{x}=2$ will grossly over-estimate number of authors with two publications. Further analysis is needed to verify, if this hold for higher number of publications also. The proposed approach also has some limitations regarding the calculations with alphacuts. Since the exact membership functions are not known, the me membership values are approximated.

\section{References}

1. Laing P, Pham T, Taylor LJ, Fang J. Filling the Void: A review of intragastric balloons for obesity. Dig Dis Sci. ;62(6):1399-1408(2017)

2. Flegal KM, Carroll MD, Ogden CL, et al. Prevalence and trends in obesity among US adults, 1999-2008. JAMA. ;303(3):235(2010).

3. Jirapinyo P, Thompson CC. Endoscopic bariatric and metabolic therapies: surgical analogues and mechanisms of action. Clin Gastroenterol Hepatol. ;15(5):619-630(2017)

4. Cawley J, Meyerhoefer C. The medical care costs of obesity: an instrumental variables approach. J Health Econ ;31:219-230(2012).

5. Norris SL, Zhang X, Avenell A, Gregg E, Schmid CH, Lau J. Long-term non-pharmacological weight loss interventions for adults with prediabetes. Cochrane Database Syst Rev. 18: CD005270(2005).

6. Yanovski SZ, Yanovski JA. Long-term drug treatment for obesity: A systematic and clinical review. JAMA. ;311:74-86(2014).

7. Colquitt JL, Pickett K, Loveman E, Frampton GK. Surgery for weight loss in adults. Cochrane Database Syst Rev. ;(8):CD003641(2014)

8. Buchwald H, Oien DM. Metabolic/bariatric surgery worldwide 2011. Obes Surg. ;23:427_ 436(2013).

9. Yorke E, Switzer NJ, Reso A, Shi X, de Gara C, Birch D, Gill R, Karmali S. Intragastric balloon for management of severe obesity: a systematic review. Obes Surg. Sep;26(9):22482254(2016)

10. Kumar N, Bazerbachi F, Rustagi T, TR MC, Thompson CC, Galvao Neto MP, et al. The influence of the Orbera intragastric balloon filling volumes on weight loss, tolerability, and adverse events: a systematic review and meta-analysis. Obes Surg. ;27:2272-2278(2017).

11. Kotzampassi K, Grosomanidis V, Papakostas P, Penna S, Eleftheriadis E. 500 intragastric balloons: what happens 5 years thereafter? Obes Surg. ;22(6):896-903(2012)

12. Kotzampassi K, Shrewsbury AD, Papakostas P, Penna S, Tsaousi GG, Grosomanidis V. Looking into the profile of those who succeed in losing weight with an intragastric balloon. J Laparoendosc Adv Surg Tech A. ;24:295-301(2014).

13. Ellegaard O, Wallin JA. The bibliometric analysis of scholarly production: How great is the impact? Scientometrics. ;105:1809-1831(2015). 
14. Mishra L, Pattnaik P, Kumar M, Aggarwal S, Misra SR. A bibliometric analysis of two PubMed-indexed high-impact factor endodontic journals: A comparison of India with other countries. Indian J Dent. Sep;7(3):121-125(2016).

15. Thompson DF, Walker CK. A descriptive and historical review of bibliometrics with applications to medical sciences. Pharmacotherapy. ;35:551-559(2015).

16. Khan NR, Thompson CJ, Taylor DR, Venable GT, Wham RM, Michael LM 2nd, Klimo P Jr. An analysis of publication productivity for 1225 academic neurosurgeons and 99 departments in the United States. J Neurosurg. ;120(3):746-55(2014).

17. Sweileh WM, Zyoud SH, Al-Jabi SW, Sawalha AF. Worldwide research productivity in emergency contraception: a bibliometric analysis. Fertil Res Pract. ;1:6(2015).

18. Zyoud SH, Al-Jabi SW, Sweileh WM. Worldwide research productivity of paracetamol (acetaminophen) poisoning: a bibliometric analysis (2003- 2012). Hum Exp Toxicol. ;34:1223(2015).

19. Kotzampassi K, Eleftheriadis E. Intragastric balloon as an alternative procedure for morbid obesity. Ann Gastroenterol. ;19:285-8(2006).

20. Kotzampassi K, Shrewsbury AD. Intragastric balloon: ethics, medical need and cosmetics. Dig Dis. ;26:45-8(2008).

21. Fernandes M, Atallah AN, Soares BGO, et al. Intragastric balloon for obesity. Cochrane Database Syst Rev. ;(1):CD004931(2007).

22. Papavramidis TS, Grosomanidis V, Papakostas P, Penna S, Kotzampassi K. Intragastric balloon fundal or antral position affects weight loss and tolerability. Obes Surg. ;22:9049(2012)

23. .Golyandina, N., Nekrutkin, V., \& Zhigljavsky, A,. Analysis of Time Series Structure: SSA and Related Techniques. New York-London: Chapman \& Hall/CRC(2001).

24. Hassani, H.. Singular spectrum analysis: Methodology and comparison. Journal of Data Science, 5(2), 239-257,(2007).

25. Buckley, J. J. , Fuzzy statistics: hypothesis testing. Soft Computing, 9(7), 512-518,2005.

26. Sfiris, D. S., \& Papadopoulos, B. K. , Non-asymptotic fuzzy estimators based on confidence intervals, Information Sciences, 279, 446-459,(2014).

27. Dabi Y, Darrigues L, Katsahian S, Azoulay D, De Antonio M, Lazzati A, Publication Trends in Bariatric Surgery: a Bibliometric Study. Obes Surg. Nov;26(11):2691-2699(2016)

28. Aminian A, Brethauer SA, Schauer PR. Citation Analysis in Bariatric Surgery. Obes Surg ;25:2417-8(2015)

29. Ozsoy Z, Demir E. The Evolution of Bariatric Surgery Publications and Global Productivity: A Bibliometric Analysis. Obes Surg. ; . doi: 10.1007/s11695-017-2982-1 (2017)

30. Dabi Y, Darrigues L, Katsahian S, Azoulay D, De Antonio M, Lazzati A. Publication Trends in Bariatric Surgery: a Bibliometric Study. Obes Surg. ; 26:2691-2699(2016).

31. Ozsoy Z, Demir E. Which Bariatric Procedure Is the Most Popular in the World? A Bibliometric Comparison. Obes Surg. ; in press. doi: 10.1007/s11695-018-3163-6(2018) 


\section{Appendix}

Let $X$ be a universal set. A fuzzy set is defined as any function of the form $A: X \rightarrow$ $[0,1] . A(x)$ is the membership degree of $x$ in the fuzzy set $A$. The $\alpha$-cuts of a fuzzy set $A$ are defined as the sets:

$$
{ }^{\alpha} A=\{x \in R: A(x) \geq \alpha\}, \alpha \in(, 0,1]
$$

The $\alpha$-cuts of a fuzzy number $A$ can written as intervals of the form

${ }^{\alpha} A=\left[A_{1}(\alpha), A_{2}(\alpha)\right]$ where $A_{1}(\alpha), A_{2}(\alpha)$ can be regarded as functions on $[0,1]$

1. $A_{1}(\alpha)$ is left continuous and non-decreasing

2. $A_{2}(\alpha)$ is right continuous and non-increasing

3. $A_{1}(\alpha) \leq A_{2}(\alpha)$

\section{Non-Asymptotic fuzzy estimators}

Buckely 2005 introduced fuzzy estimators. Papadopoulos and Sfiris,2014 generalize fuzzy fuzzy estimators and showed new ways to construct them.

Let $X_{1}, X_{2}, \ldots X_{n}$ be a random sample of size $n$ from a distribution with unknown parameter $\theta$ and let $\left[\theta_{1}(\alpha), \theta_{2}(\alpha)\right]$ denote the $(1-\alpha) 100 \%$ confidence intervals for $\theta$. Using any monotonic, continuous and onto function:

$h(\alpha):(0,1] \rightarrow\left[\frac{\gamma}{2}, 0.5\right], \gamma \in(0,1)$, then a family of fuzzy estimators is derived by the following super-imposed intervals:

${ }^{\alpha} \tilde{\theta}_{\gamma}=\left[\theta_{1}(2 h(\alpha)), \theta_{2}(2 h(\alpha))\right], \alpha \in(0,1]$

It is shown that these fuzzy estimators are non-asymptotic and proper fuzzy numbers with compact support. Note that the explicit membership function can also be derived as :

$$
\tilde{\theta}_{\gamma}(u)=\min \left\{\theta_{1}^{-1}(u),-\theta_{2}^{-1}(-u), 1\right\}
$$

For the confidence interval of the mean, this membership function can be derived as:

$A_{\mu}(x)=\left\{\begin{array}{c}\frac{2}{1-\gamma} \mathrm{F}\left(\frac{x-\bar{x}}{\sigma / \sqrt{n}}\right)-\frac{\gamma}{1-\gamma}, \bar{x}-\frac{\sigma}{\sqrt{n}} \Phi^{-1}\left(1-\frac{\gamma}{2}\right) \leq \bar{x} \\ \frac{2}{1-\gamma} \mathrm{F}\left(\frac{\bar{x}-x}{\sigma / \sqrt{n}}\right)-\frac{\gamma}{1-\gamma}, \bar{x} \leq \bar{x}+\frac{\sigma}{\sqrt{n}} \Phi^{-1}\left(1-\frac{\gamma}{2}\right) \\ 0 \quad \text { otherwise }\end{array}\right.$

The $\alpha$-cut of this fuzzy number is :

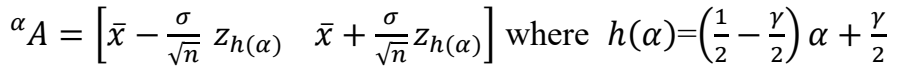

For unknown $\sigma, \sigma / \sqrt{n}=\frac{s}{\sqrt{n}}$ and $z_{h(\alpha)}=t_{h(\alpha)}$ where $t_{h(\alpha)}$ is the T-distribution with $n-1$ degrees of freedom.

The arithmetic operations can be performed on the alpha-cuts(see Papadopoulos and Sfiris, 2014 